\title{
Cutaneous haemangioendothelioma: a possible link with chronic exposure to vinyl chloride
}

\author{
Michaela F P Davies, M Curtis, J M T Howat
}

\begin{abstract}
A patient who worked with polyvinyl chloride developed a malignant haemangioendothelioma of a toe. This rare tumour is more commonly found in the liver where it has been reported to arise in association with exposure to the vinyl chloride monomer.
\end{abstract}

Malignant haemangioendothelioma, or angiosarcoma, is a rare tumour of vascular endothelium. It may arise in any tissue but has been reported most commonly in muscle, bone, breast, and liver. ${ }^{12}$ Cutaneous forms, first described by Wilson-Jones, ${ }^{3}$ may arise in the scalp and face of elderly patients. ${ }^{46}$ Both previous trauma and radiotherapy have been implicated in their aetiology. ${ }^{256}$ The histological features are identical with those of the postmastectomy angiosarcoma (Stewart-Treves syndrome) that may occur in a chronically oedematous arm after mastectomy and radiotherapy. ${ }^{357}$ Our patient developed a cutaneous haemangioendothelioma after working for many years with polyvinyl chloride (PVC); the monomeric form of which, VCM, has been incriminated in the development of similar tumours found in the liver. ${ }^{89}$

\section{Case report}

A 55 year old man presented with a three month history of an ulcerating lesion affecting the nail bed of his third left toe. This had not responded to simple dressings and antifungal agents. He had worked in the plastics industry for many years first as a welder and then for 28 years as a moulder of polyvinyl chloride. His medical history was unremarkable, although two years previously he had developed a rash, thought to be psoriasis, which had spontaneously resolved. He had been a heavy drinker in the past and still consumed 20-30 pints of beer a week.

Examination of his toe showed the nail bed to be split by a raised moist lesion (fig 1). There was no

Department of Surgery, North Manchester General Hospital, Manchester M8 6RB

Michaela F P Davies, J M T Howat

Department of Pathology, North Manchester Hospital, Manchester M8 6RB

M Curtis inguinal lymphadenopathy and no hepatomegaly. Radiographic examination of the toe was unremarkable and, with the exception of a mild rise in the hepatic enzymes, both haematological and biochemical results were normal, as was ultrasonic examination of the liver. The lesion was biopsied under local anaesthesia. Histological examination showed a malignant haemangioendothelioma with plump cells in a loose connective tissue stroma. In some places they were in clumps; in others they formed capillary sized channels with open lumina. There was pronounced cellular pleomorphism and many bizarre mitotic figures. Reticulin fibres were seen frequently around the cells (figs 2 and 3 ) and many of the cells were stained positively with factor VIII related antigen with silver enhancement and with a special lectin stain (UEA-1), a feature typical of tumours arising from vascular endothelium. ${ }^{356}$ Amputation was carried out through the metacarpophalangeal joint. Twelve months later there was no evidence of local or distant recurrence.

\section{Discussion}

Malignant haemangioendothelioma or angiosarcoma, although uncommon, may arise after exposure to certain chemical agents-for example, arsenic and thorium dioxide. ${ }^{10}$ More recently a link has been well established between haemangioendothelioma of the liver and the production of polyvinyl chloride (PVC),

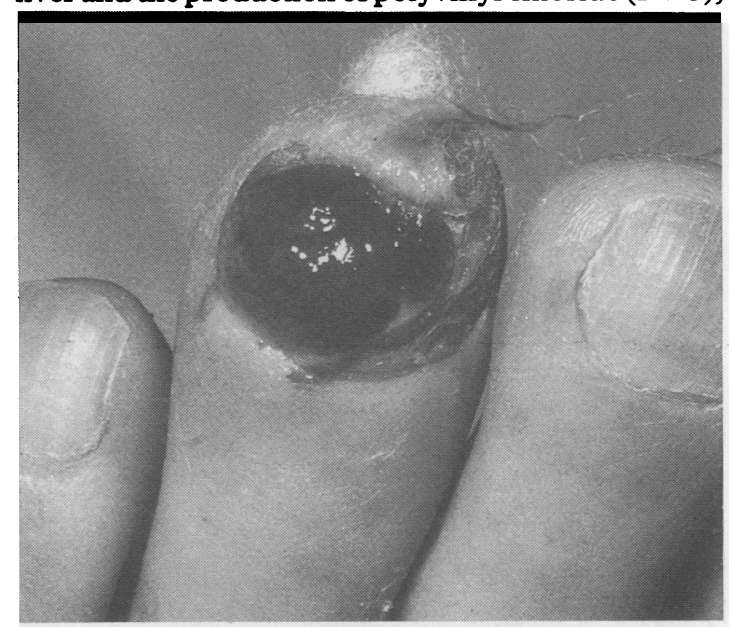

Figure 1 Tumour at presentation. 


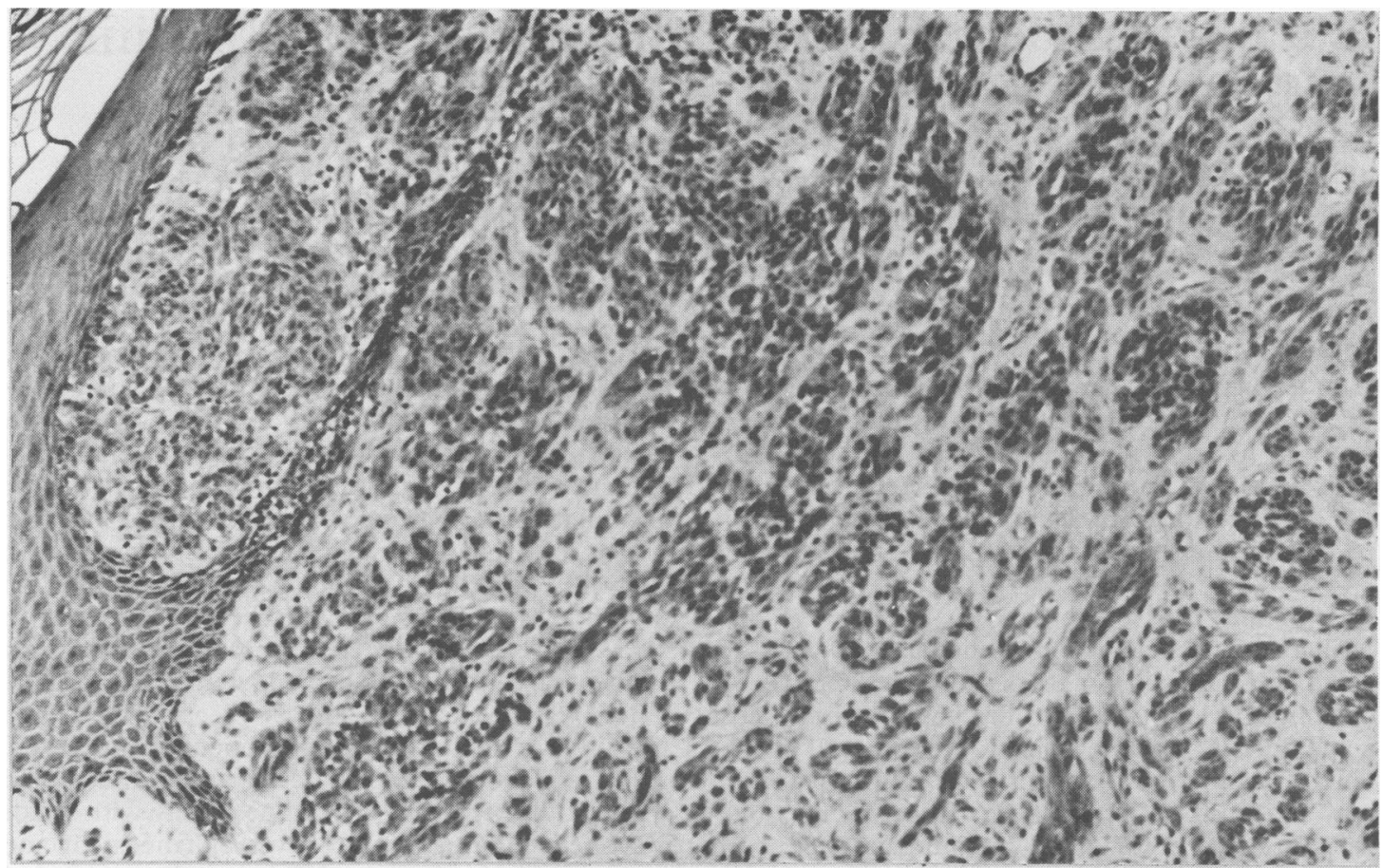

Figure 2 Cutaneous haemangioendothelioma (hematoxylin and eosin $\times 40$ ).

118 cases being recorded by $1984 .^{891112}$ Although the like skin changes, which regress when exposure manufacture of PVC has been associated with a syndrome that may include Raynaud's phenomenon, lytic lesions of the distal phalanges and scleroderma ceases (occupational acro-osteolysis), ${ }^{1314}$ a cutaneous malignant haemangioendothelioma has not been previously reported. It has been shown, however,

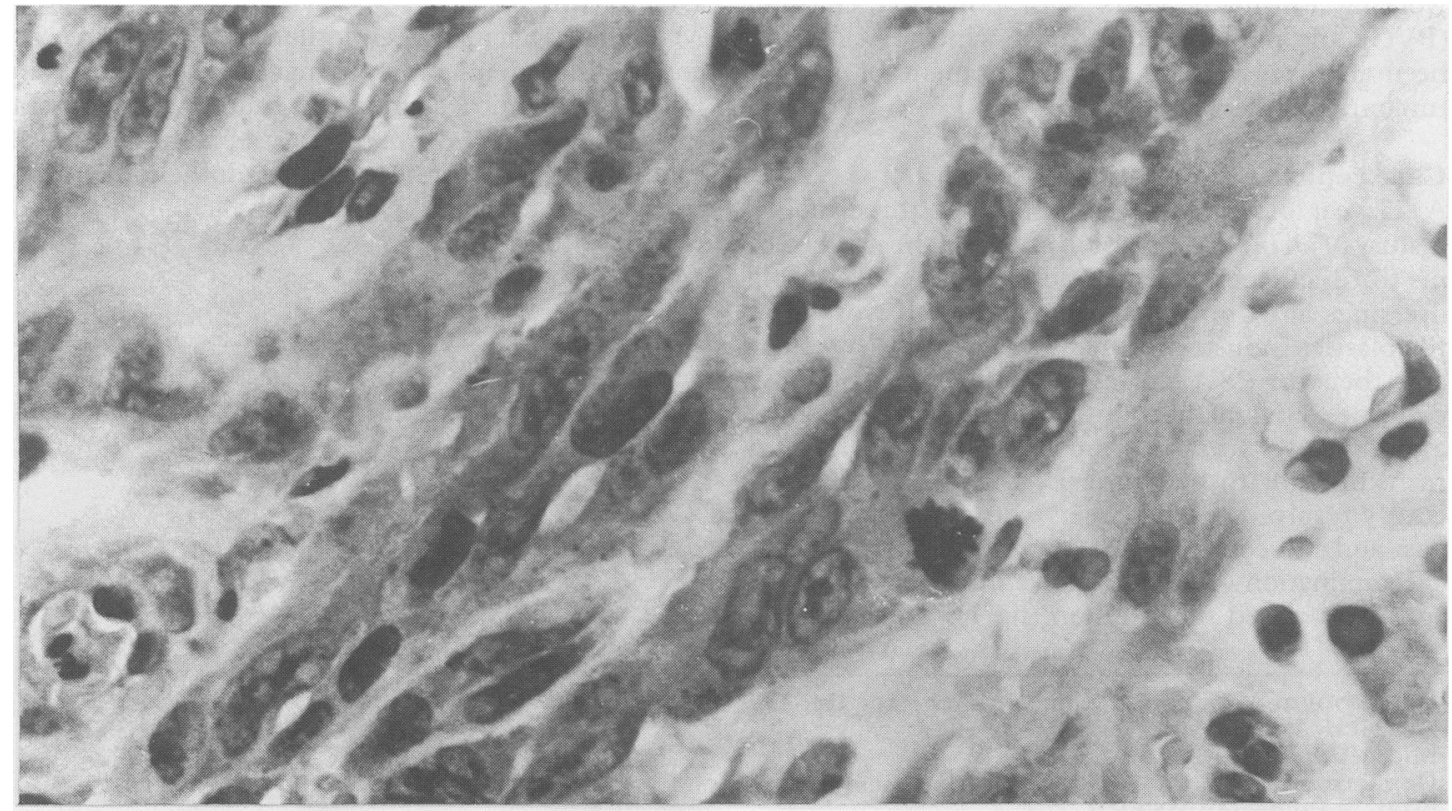

Figure 3 Cutaneous haemangioendothelioma (hematoxylin and eosin $\times 400$ ). Tumour cells lining vascular channels are identical with those arranged in solid nests. 
that molecules from both VCM and, perhaps more important, its metabolites, appear in the skin of rats within hours of inhalation of ${ }^{14} \mathrm{C}$-labelled VCM, ${ }^{15} 16$ and epidermoid carcinomas have been described in the facial areas of rats experimentally exposed to vinyl chloride. ${ }^{117}$ There seems no doubt that some elements of the skin are susceptible to the oncogenic effects of VCM although, with the exception of liver malignancies, no increase in the incidence of deaths from cancers has been observed in man in association with exposure to VCM. ${ }^{18}$

To date, cases of haemangioendothelioma have been identified exclusively in workers engaged in the process of polymerising VCM to PVC but not in those exposed only to the finished polymer or processing it into plastic products. Although high levels are required, exposure need not be continuous. ${ }^{12} 19$ Those who clean the pressure vessels used to polymerise vinyl chloride at high temperatures seem particularly at risk but hepatic tumours may also occur in production workers and others engaged in the industry. ${ }^{8}$ During the manufacture of PVC some of the VCM remains absorbed on the finished polymer at a concentration of $0.005 \%$ or higher. ${ }^{19} 20$ Release of small amounts of monomer may subsequently occur during handling and processing finished articles from raw PVC. The significance of this small exposure is uncertain. ${ }^{1921}$ Our patient had direct contact with PVC over many years and in moulding or welding PVC at high temperatures it seems likely that small quantities of the monomer may be released, although for practical purposes it is considered to be infinitesimally small and to be undetectable (B Bennett, personal communication).

The possibility that the lesion on the toe was a cutaneous metastasis from a primary hepatic tumour is excluded by the normal ultrasound of the liver and the continuing good health of the patient. The biochemical evidence of mild hepatic dysfunction probably reflects excessive alcohol consumption rather than exposure to VCM. ${ }^{22}$ That the tumour in the present case was a subungual amelanotic malignant melanoma is excluded by the positive staining by specific histochemical markers for tumours of vascular endothelium. It is of interest, however, that Heldass et al raised the possibility that a causal relation might exist between exposure to VCM and the development of cutaneous malignant melanoma ${ }^{20}$ This association has not been confirmed by more recent studies. ${ }^{18}$

The relation of PVC manufacture to hepatic angiosarcoma was only firmly established in 1974 and the tumour is known to have a long latency (2030 years). More cases may be expected to arise over the next three decades despite changes in legislation to ensure that workers are exposed to lower levels of VCM. ${ }^{818}$ If the cutaneous angiosarcoma in the present case has occurred as a result of exposure to VCM then similar lesions may be encountered in the future.

We are most grateful for the advice and guidance given by Dr Brian Bennett of ICI Chemicals and Polymers Ltd during the preparation of this manuscript.

1 Silva LG, Capitao-Mor MM. Angioendothelioma maligno. Acta Med Port 1981;3:51-6.

2 Mehregan AH, Usndek HE. Malignant angioendothelioma. Arch Dematol 1976;112:1565-7.

3 Wilson-Jones $\mathrm{E}$. Malignant angioendothelioma of the skin. $\mathrm{Br} \mathrm{J}$ Dermatol 1964;76:21-39.

4 Holden AC, Spittle MF, Wilson-Jones E. Angiosarcomas of the face and scalp; prognosis and treatment. Cancer 1987;59: 1046-57.

5 Hori Y. Malignant haemangioendothelioma of the skin. $J$ Dermatol Surg Oncol 1981;7:130-6.

6 Girard C, Johnson WC, Graham JH. Cutaneous angiosarcoma. Cancer 1970;26:868-83.

7 Stewart FW, Treves N. Lymphangiosarcoma in postmastectomy limbs. Cancer 1948;1:64-81.

8 Forman D, Bennett B, Stafford J, Doll R. Exposure to vinyl chloride and angiosarcoma of the liver; a report of the register of cases. Br J Ind Med 1985;42:750-3.

9 Sugita M, Masuda Y, Tsuchiya K. Early detection and signs of hepatoangiosarcoma among vinyl chloride workers. Am J Ind Med 1986;10:411-7.

10 Popper H, Thomas LB, Telles NG, Falk H, Selikoff IJ. Development of hepatic angiosarcoma in man induced by vinyl chloride, thorotrast and arsenic: comparison with cases of unknown aetiology. Am J Pathol 1978;92:349-76.

11 Creech JL, Johnson MN. Angiosarcoma of the liver in the manufacture of polyvinyl chloride. J Occup Med 1974;3: $150-1$.

12 Dannaher CL, Tamburro CH, Yam LT. Occupational carcinogenesis: the Louisville experience with vinyl chloride associated hepatic angiosarcoma. Am J Med 1981;70:279-87.

13 Harris DK, Adams WGF. Acro-osteolysis in men engaged in the polymerisation of vinyl chloride. $\mathrm{Br}$ Med J 1967;iii:712-4.

14 Wilson RH, McCormick WE, Tatum CE, Creech JL. Occupational acro-osteolysis. JAMA 1967;201:83-7.

15 Watanabe PG, McGowan GR, Madrid EO, Gehring PJ. Fate of $\left({ }^{14} \mathrm{C}\right)$ vinyl chloride following inhalational exposure in rats. Toxicol Appl Pharmacol 1976;37:49-59.

16 Duprat P, Fabry JP, Gradiski D, Magadur JL. Metabolic approach to industrial poisoning: blood kinetics and distribution of ${ }^{14} \mathrm{C}$-vinyl chloride monomer (VCM). Acta Pharmacol Toxicol 1977;41, suppl 1:142-5.

17 Viola PL, Bigotti A, Caputo A. Oncogenic response of rat skin, lungs and bones to vinyl chloride. Cancer Research 1971; 31:516-9.

18 Jones RD, Smith DM, Thomas PG. A mortality study of vinyl chloride monomer workers employed in the United Kingdom in 1940-1974. Scand J Work Environ Health 1988;14:153-60.

19 Barnes AW. Vinyl chloride and the production of PVC. Proceedings of the Royal Society of Medicine 1976;69:277-81.

20 Heldass SS, Langard SL, Andersen A. Incidence of cancer among vinyl chloride and polyvinyl chloride workers. $\mathrm{Br} J$ Ind Med 1984;41:25-30.

21 Baxter PJ. Epidemiological studies of PVC manufacturers and fabricators and primary angiosarcoma of the liver. Proceedings of the Royal Society of Medicine 1976;69:297-9.

22 Duck BW. Medical surveillence of vinyl chloride workers. Proceedings of the Royal Society of Medicine 1976;69:307-9.

Accepted 3 April 1989 